\title{
Boerhaave's Syndrome: Presenting with Chest Pain
}

The Editor,

Sir,

Boerhaave Syndrome or spontaneous oesophageal rupture is a rare, potentially fatal condition (1-3). Patients usually present with pain, dyspnoea and signs of shock after forced vomiting (4). The Meckler triad consisting of vomiting, pain and subcutaneous emphysema is characteristic for Boerhaave Syndrome, although it is observed in only $30-50 \%$ of affected patients $(5,6)$. We present a case report of Boerhaave's syndrome presenting with chest pain after vomiting.

A 47-year-old woman presented to our Emergency Department after sudden, left-sided chest pain after vomiting. On admission, her general status was moderately well. On physical examination, her breath sounds were diminished on the left haemithorax. A chest X-ray taken for diminished breath sounds on the left haemithorax showed pneumothorax and pleural effusion in the left haemithorax (Fig. 1).

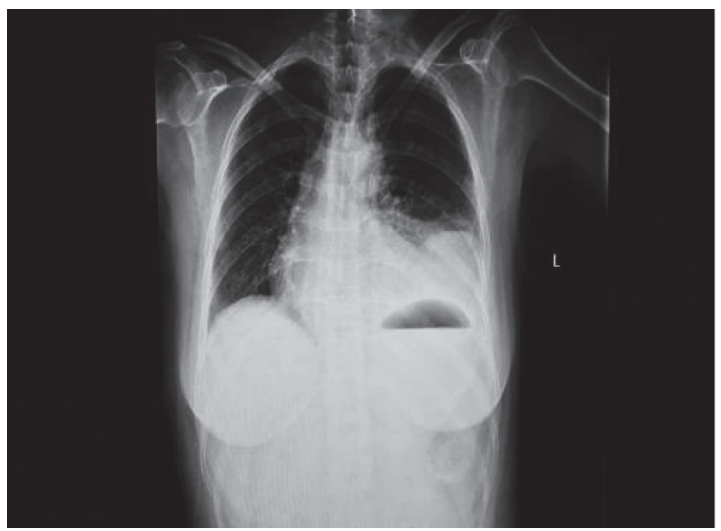

Fig. 1: Chest X-ray: Left haemithorax showed pneumothorax and pleural effusion.

A thoracic computerized tomography (CT) was performed, which showed left-sided pneumothorax, pneumomediastinum, distal paraesophageal air-fluid densities (oesophageal perforation?), bilateral pleural effusion with left predominance and rightward mediastinal shift (Figs. 2A, B).

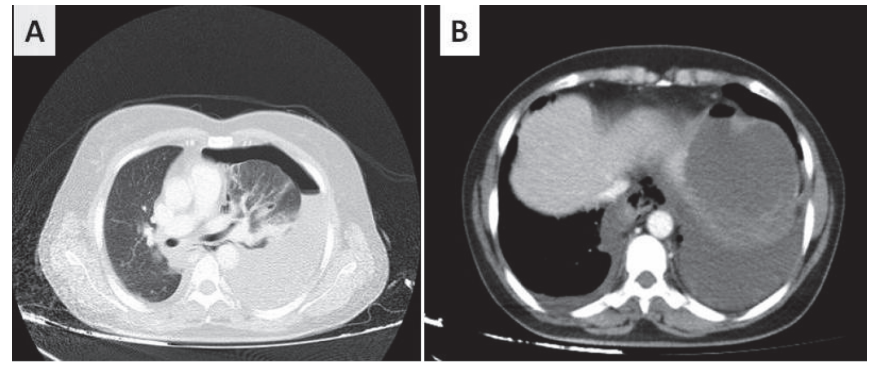

Fig. 2: Thoracic computerized tomography (CT):

A:Showed left-sided pneumothorax, pneumomediastinum, distal paraesophageal air-fluid densities and rightward mediastinal shift.

B: Bilateral pleural effusion with left predominance.

The patient was referred to the Thoracic Surgery Department and a tube thoracostomy was performed. It was immediately noted that gastric contents drained out of the tube (Fig. 3).

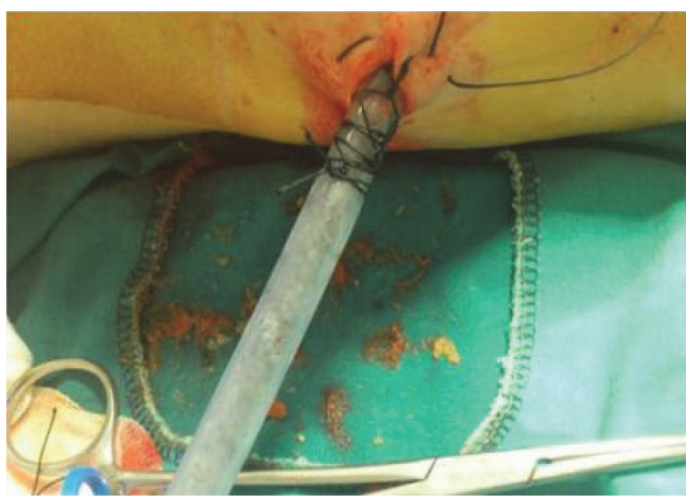

Fig. 3: Tube thoracostomy; the gastric content was observed in tube thoracostomy.

Thus, the patient was referred to the General Surgery Department for suspected oesophageal rupture. A fluoroscopy was performed, after which the patient deteriorated and was urgently taken into operation. The distal oesophagus was resected and the patient was transferred to the intensive care unit for postoperative respiratory failure. She also developed fever at follow-up and died on $22^{\text {th }}$ day of admission.

Boerhaave syndrome, or spontaneous oesophageal rupture, was first defined by Boerhaave in $1724(2,5,6)$. The syndrome is usually characterized by chest pain that occurs after forceful vomiting or gagging $(6,7)$. The initial symptoms first suggest myocardial infarction, spon- 
taneous pneumothorax, perforated ulcer, acute pancreatitis, aortic dissection, or pulmonary disease $(3,5,8,9)$. The index patient was admitted to the Emergency Department with chest pain that developed after vomiting.

In our patient, acute coronary syndrome, pneumothorax and haemothorax were considered in the differential diagnosis. The diagnosis of the condition may be considerably delayed owing to not giving consideration to oesophageal perforation or the case may be misdiagnosed as other conditions (4). Chest X-ray usually demonstrates pleural effusion, pneumothorax, hydropneumothorax, pneumoperitoneum and retropneumoperitoneum. Endoscopy can be used for diagnosis in patients who are suspected to have oesophageal rupture but who have negative radiological tests (1).

Thoracentesis or thoracic drainage can also be used to confirm the diagnosis (9). A thoracic CT was obtained in our patient upon detection of pneumothorax and pleural effusion on chest X-Ray. The thorax CT demonstrated signs of oesophageal rupture and the chest tube drained gastric contents; oesophageal perforation was considered in the differential diagnosis and the patient was operated on an urgent basis (8). A delayed diagnosis may confer a substantially increased mortality risk (4). Death usually occurs as a result of infectious mediastinal complications and septic shock $(1,5,10)$. Our patient died despite a diagnosis within the first 3-4 hours and urgent surgical intervention.

Oesophageal rupture should be suspected especially in patients presenting to Emergency Departments with chest pain after vomiting. Further tests and imaging should be performed without delay.

Keywords: Boerhaave Syndrome, chest pain, diagnosis
S Bozkurt, IG A Ăar, MA Kartal, A Köse, C Ayrik, H Narci

From: Emergency Medicine Department, Medical Faculty Mersin University, Turkey.

Correspondence: Dr S Bozkurt, Emergency Medicine Department, Medical Faculty Mersin University, Turkey. Email:seyranbozkurt@yahoo.com

\section{REFERENCES}

1. Soreide JA, VisteA. Esophageal Perforation: Diagnostic work-up and clinical decision making in the first 24 Hours. Scand J Trauma Resusc Emerg Med 2011; 19: 66.

2. Teh E, Edwards J, Duffy J, Beggs D. Boerhaave's Syndrome: A review of management and outcome. Interact Cardiovasc Thorac Surg 2007; 6: 640-3.

3. Tonolini M, Bianco R. Spontaneous Esophageal Perforation (Boerhaave Syndrome): Diagnosis With CT-Esophagography. J Emerg Trauma Shock 2013; 6: 58-60.

4. Zanini G, Pelati A, Racheli M, Virgillo A, Bortolotti M, Pasini GF. Boerhaave's syndrome - A difficult differential diagnosis of chest pain. Kardiol Pol 2010; 689: 1040-2.

5. Hingston CD, Saayman AG, Frost PJ, Wise MP. Boerhaave's Syndrome-rapidly evolving pleural effusion; A radiographic clue. Minerva Anestesiol 2010; 76: 865-7.

6. Xia M, Pustilnik S. Boerhaave syndrome resulting from homicidal blunt trauma. Am J Forensic Med Pathol 2014; 35: 176-7.

7. Antonis JHA, Poeze M, Heurn L WEV. Boerhaave's syndrome In Children: A cease report and review of the literature. J Pediatr Surg 2006; 41: 1620-23.

8. Chirica M, Champault A, Dray X, Sulpice L, Munoz-Bongrand N, Sarfati E et al. Esophageal perforations. J Visc Surg 2010; 147: 117-28.

9. Suzuki M, Sato N, Matsuda J, Niwa N, Murai K, Yamamoto T et al. A case of rapid diagnosis of boerhaave syndrome by thoracic drainage. J Emerg Med 2012; 43: 419-23.

10. Blencowe NS, Strong S, Hollowood AD. Spontaneous oesophageal rupture. BMJ 2013; 346: 3095. 